\title{
Aspectos semânticos
} e morfossintáticos da modalidade volitiva nos discursos de investidura de Rodríguez Zapatero

OLIVEIRA, André Silva; PRATA, Nadja Paulino Pessoa. Aspectos semânticos

e morfossintáticos da modalidade volitiva nos discursos de investidura de Rodríguez Zapatero. Entrepalavras, Fortaleza, v. 8, n. esp., p. 153-168, set. 2018
Semantic and morphosyntactic aspects of the volitive modality in Rodríguez Zapatero's investiture speeches

André Silva OLIVEIRA (UFC) andrethtzn@gmail.com

Nadja Paulino Pessoa PRATA (UFC) nadja.prata@gmail.com

Recebido em: 01 de mar. de 2018. Aceito em: 08 de jun. de 2018.
Resumo: O presente trabalho visa fazer uma análise dos aspectos semânticos e morfossintáticos para a expressão da modalidade volitiva nos discursos de investidura de Rodríguez Zapatero. À luz dos pressupostos teóricos da Gramática Discursivo-Funcional (GDF), de Hengeveld e Mackenzie (2008), pretendemos fazer a descrição e a análise da modalidade volitiva, a qual está relacionada ao que é (in)desejável. Temos a intenção de avaliar, especificamente, a manifestação dos tipos de fonte volitiva e de alvo volitivo (aspectos semânticos) e a marcação do tempo verbal e do modo verbal (aspectos morfossintáticos) para a instauração da modalidade volitiva a partir de dois discursos proferidos pelo ex-primeiro-ministro do governo espanhol, Rodríguez Zapatero, proferidos nos anos de 2004 e 2008. Em relação aos aspectos semânticos, constatamos que houve maior emprego de fonte volitiva do tipo "Enunciador", com 63,76\% das ocorrências, e de alvo volitivo do tipo "Instituição", com 76,81\% das ocorrências. No que diz respeito aos aspectos morfossintáticos, comprovamos que houve maior incidência do presente do indicativo, com $87,24 \%$, e maior ocorrência do modo indicativo, com 93,62\%. 
v. 8 (esp.)

153-168 set. 2018

Para a instauração da modalidade volitiva nos discursos de Rodríguez Zapatero, verificamos que o falante (aquele que discursa, nesse caso, o candidato a primeiroministro) prefere construir-se como fonte da atitude volitiva, instaurando as modalizações volitivas sobre as instituições (alvo volitivo), empregando, para isso, o presente do modo indicativo.

Palavras-chave: Modalidade Volitiva. Fonte e Alvo. Tempo e Modo.

Abstract: The present work aims to make an analysis of the semantic and morphosyntactic aspects for the expression of the volitive modality in the investiture speeches of Rodríguez Zapatero. In light of the theoretical assumptions of Functional Discourse Grammar (FGD), by Hengeveld and Mackenzie (2008), we intend to describe and analyze the volitive modality, which is related to what is (in) desirable. We intend to evaluate specifically the manifestation of volitive source and volitive target (semantic aspects) and the marking of tense and verbal modes (morphosyntactic aspects) for the introduction of the volitive modality from two discourses uttered by the former prime minister of the Spanish Government, Rodríguez Zapatero, issued in 2004 and 2008. Regarding the semantic aspects, we found that there was a higher incidence of volitive source of type "Enunciator", with $63.76 \%$ of occurrences, and volitive target of type "Institution", with $76.81 \%$ of occurrences. Regarding the morphosyntactic aspects, we verified that there was a higher incidence of the present indicative, with $87.24 \%$, and greater occurrence of the indicative mood, with $93.62 \%$. For the introduction of the volitive modality in the speeches of Rodríguez Zapatero, we find that the speaker (the one who speaks, in this case, the candidate for prime minister) prefers to build himself as a source of the volitive attitude, instituting volitive modalizations about the institutions (volitive target), using, for this, to employ the present in the indicative mood.

Keywords: Volitive Modality. Source and Target. Tense and Mood.

\section{Introdução}

Neste artigo, trataremos dos aspectos semânticos (fonte e alvo volitivo) e dos aspectos morfossintáticos (tempo e modo verbais) para a instauração da modalidade volitiva em língua espanhola com base na Gramática Discursivo-Funcional (GDF). Para isso, empreendemos uma análise dos modalizadores volitivos em um texto argumentativo de caráter político, o discurso de investidura, coletado em uma página web de difusão on-line. Os discursos de investidura são realizados em um contexto de produção de cunho político em que o autor, ao escrevê-los e depois proferi-los, fá-lo pensando em certos elementos comunicativos que possam produzir o efeito de sentido esperado no seu destinatário ao empregar o tempo e o modo verbais adequados para expressar a desejabilidade de determinadas ações ou eventos de cunho político. Os discursos de investidura, segundo Esteban (2011), são discursos proferidos pelos candidatos antes da realização das eleições, em que os candidatos buscam o apoio do Parlamento Espanhol, manifestandolhe suas pretensões (intencionalidades) acerca de ações políticas, econômicas, sociais etc., que serão realizadas em seu futuro mandato. 
Partindo do pressuposto de que a modalidade volitiva relacionase ao que é desejável (HENGEVELD; MACKENZIE, 2008), fizemos uma análise desta categoria em relação aos aspectos semânticos e morfossintáticos. Para a análise e descrição dessas categorias de análise, elaboramos o nosso corpus a partir de dois discursos de investidura proferidos pelo candidato a primeiro-ministro do governo espanhol, Rodríguez Zapatero, nas eleições de 2004 e 2008.

Em relação à organização deste trabalho, dividimo-lo em quatro seções, que versam respectivamente sobre: (i) a modalidade volitiva na perspectiva da Gramática Discursivo-Funcional (GDF), de Hengeveld; Mackenzie (2008); (ii) a metodologia, na qual consta a delimitação do corpus e as categorias de análise; (iii) a análise quali-quantitativa das ocorrências, tendo em vista o corpus constituído para a investigação; e (iv) as considerações finais.

\section{A modalidade volitiva na Gramática Discursivo-Funcional (GDF)}

A Gramática Discursivo-Funcional (GDF), segundo Hengeveld; Mackenzie (2008), trata-se de uma teoria estrutural-funcional da linguagem, de organização descendente (top-down), que visa alcançar adequação psicológica e que toma o Ato Discursivo como unidade básica de análise, no intuito de alcançar a adequação pragmática. A GDF coloca em foco o Componente Gramatical de uma teoria da interação verbal, e, por isso, pretende explicar tanto fenômenos linguísticos que só podem ser entendidos em níveis mais amplos, como também descrever expressões linguísticas com sentido completo e que são menores que a frase.

Na teoria da GDF, a categorização da modalidade é feita a partir de dois parâmetros: (i) o alvo de avaliação, que corresponde ao enunciado modalizado, podendo a modalidade estar orientada-para-o-participante (refere-se à relação entre o participante expresso no predicado, ou as propriedades desse participante, e a realização potencial do evento descrito no predicado), orientada-para-o-evento (trata-se da descrição de um evento contida dentro do enunciado, mas sem que o falante faça uma avaliação subjetiva deste), ou orientada-para-a-proposição (relaciona-se com a parte do enunciado que descreve as crenças e as visões do falante, especificando o grau de comprometimento dele em relação à proposição que ele apresenta) ${ }^{1}$; (ii) o domínio semântico, que

\footnotetext{
${ }^{1}$ Em trabalhos mais recentes acerca da categoria modalidade, constatamos a existência de uma orientação modal para o Episódio, que versa sobre a caracterização de um episódio em termos de sua possibilidade ou impossibilidade de que venha a ocorrer em relação ao conhecimento de mundo do falante (Cf. DALL'AGLIO HATTNHER; HENGEVELD, 2016).
} 
v. 8 (esp.)

153-168 set. 2018

se relaciona ao tipo de avaliação modal que se faz, podendo a categoria modalidade dividir-se em: facultativa, deôntica, volitiva, epistêmica e evidencial ${ }^{2}$.

Especificamente, em relação ao domínio semântico, a modalidade volitiva está relacionada ao que é (in)desejável ao falante ou ao participante expresso no predicado. No que diz respeito ao alvo da avaliação (ou orientação modal), ela pode ter orientação para o Participante, o Evento, o Episódio 3 ou a Proposição. A modalidade volitiva orientada-para-o-participante descreve o desejo de um participante de se engajar no evento descrito pelo predicado, como em: Nós queremos ir4. A modalidade volitiva orientada-para-o-evento caracteriza eventos em termos do que é geralmente (in)desejável, mas sem que o falante fizesse uma avaliação acerca dessa desejabilidade, como em: Seria ruim se eu quebrasse isso ${ }^{5}$. Na modalidade volitiva orientada-para-a-proposição, o falante faz uma asserção acerca do que lhe parece desejável, sendo o conteúdo proposicional relacionado às crenças do falante e ligado a não-factualidade (em termos não abstratos): Quero dormir/ Isso vai dormir em mim6. Para Oliveira (2017), a modalidade volitiva poderia também estar orientada-para-o-episódio, que se refere à avaliação que é feita pelo falante em relação à desejabilidade do participante expresso no predicado, tendo o modalizador volitivo como escopo de um ou mais estado-de-coisas tematicamente coerentes e com referência a um episódio localizado no passado: Talvez Maria, não me lembro bem a frase, estou citando ou quero citar o fato, no momento da cruz de sua fidelidade, tivesse tido vontade de dizer: e Este que me disseram que ia salvar a Israel? Enganaram-me! Não disse e nem se permitiu dizer, porque era a mulher que sabia que tudo que havia recebido foi gratuitamente?

\footnotetext{
${ }^{2}$ Em trabalhos mais recentes sobre os subtipos de modalidade dentro da GDF, temos que a modalidade evidencial não se trataria mais de um subtipo de modalidade, mas de uma categoria, a Evidencialidade (Cf. DALL'AGLIO HATTNHER; HENGEVELD, 2016).

3 A modalidade volitiva orientada-para-o-episódio é proposta em Oliveira (2017).

4 Tradução nossa. O original diz: "We want to leave" (HENGEVELD, 2008, p. 213).

5 Tradução nossa. O original diz: "It would be bad if I broke it" (HENGEVELD, 2008, p. 176).

6 Tradução nossa. O original diz: "I want to sleep/It's going to sleep on me" (HENGEVELD, 2008, p. 154).

7 Tradução de Oliveira (2017). O original diz: "[...] quizás María, no recuerdo bien la frase, estoy citando o quiero citar el hecho, en el momento de la cruz de su fidelidad, hubiera tenido ganas de decir ¿y Éste me dijeron que iba a salvar a Israel? ¡Me engañaron! no lo dijo ni se permitió decirlo, porque era la mujer que sabía que todo lo había recibido gratuitamente" (OLIVEIRA, 2017, p. 196).
} 
Além do domínio semântico e do alvo da avaliação (ou orientação modal), levamos em consideração, para a modalidade volitiva, alguns aspectos semânticos (valor semântico, fonte e alvo volitivos) ${ }^{8}$ e morfossintáticos (tempo e modo verbais). No que concerne ao valor semântico da modalidade volitiva, reportamos o trabalho de Oliveira, Nogueira e Prata (2017), que apresenta três valores: (i) volição (desejo propriamente dito); (ii) volição-exortativa (desejo como uma exortação); e (iii) volição-irrealizável (desejo relacionado a um fato passado) ${ }^{9}$.

No que diz respeito aos aspectos semânticos, verificamos, segundo García (2009), que o desejo (volição) pressupõe a existência de um sujeito que deseja (fonte volitiva), de uma ação desejada, sendo essa ação real ou irreal, e de um sujeito da ação desejada (alvo volitivo). Dessa forma, para a volição expressa nos discursos do candidato a primeiroministro, pautamos que a modalidade volitiva pode ter como fonte volitiva (o sujeito que deseja - S1) o próprio falante, sendo, portanto, classificado como fonte do tipo Enunciador. Quando o falante reportar a volição de outra pessoa, classificá-la-emos como fonte do tipo Indivíduo e, quando reportar a volição de uma instituição, seja essa instituição religiosa, civil, jurídica, etc., iremos designá-la como fonte do tipo Instituição. Para os desejos de âmbito coletivo que forem reportados pelo candidato, designá-lo-emos como fonte do tipo Domínio Comum.

Para o alvo volitivo, o sujeito da ação desejada (S2), sobre quem irá recair aquilo que é desejado pelo sujeito que deseja (S1), podemos estabelecer os seguintes critérios: para os casos em que a desejabilidade recair sobre o próprio falante, iremos designar como alvo do tipo Enunciador. Nos casos em que a desejabilidade recair sobre uma pessoa (ou grupo de pessoas) em particular, classificá-lo-emos como alvo volitivo do tipo Indivíduo e, para os casos em que recair sobre alguma instituição, seja ela religiosa, civil, jurídica, etc., designá-lo-emos como alvo do tipo Instituição. Para os casos em que a volição recair sobre os ouvintes a quem a fonte volitiva fala diretamente, defini-lo-emos como Coenunciador.

No que diz respeito às categorias de análise referentes aos aspectos morfossintáticos, o desejo (volição), de acordo com García (2009), pode manifestar-se em língua espanhola, em relação ao tempo verbal, por

\footnotetext{
${ }^{8}$ Para a classificação dos tipos de fonte e alvo volitivos, utilizamos os trabalhos de Pessoa (2011), do qual fizemos uma adaptação para a modalidade volitiva.

9 Em Oliveira (2017), há uma reformulação desses valores semânticos, a saber: desideração (volição irrealizável), optação (volição realizável), intenção (volição como intenção) e exortação (volição como ordem ou mandado).
} 
v. 8 (esp.)

153-168 set. 2018

meio do: presente, pretérito perfeito simples, pretérito perfeito composto, pretérito mais-que-perfeito composto, pretérito imperfeito, condicional simples, condicional composto, futuro simples e futuro composto ${ }^{10}$; e, em relação ao modo verbal, por meio do: indicativo, subjuntivo e imperativo.

Tendo por base essas categorias de análise e, tendo em vista o propósito desta pesquisa que consiste em descrever e analisar a modalidade volitiva, optamos pelos dois discursos de investidura proferidos por Rodríguez Zapatero nos anos de 2004 e 2008, como veremos na seção seguinte.

\section{Metodologia}

Tendo em vista a descrição e análise dos aspectos semânticos e morfossintáticos para a instauração da modalidade volitiva em língua espanhola, optamos pelos discursos de investidura de Rodríguez Zapatero ${ }^{11}$. Vejamos o Quadro 1 abaixo:

Quadro 1 - Os discursos de investidura de Rodríguez Zapatero

\begin{tabular}{|c|c|c|c|}
\hline $\begin{array}{c}\text { Discursos de } \\
\text { Investidura }\end{array}$ & Data & Link da página web & $\begin{array}{c}\text { Quantidade } \\
\text { de Palavras }\end{array}$ \\
\hline Rodríguez Zapatero & $\begin{array}{c}15 \text { de abril } \\
\text { de } 2004\end{array}$ & $\begin{array}{c}\text { Disponível em: <http://bit. } \\
\text { ly/2CrGAjE> } \\
\text { Acesso em: } 16 \text { mar. 2016. }\end{array}$ & 7.700 \\
\hline Rodríguez Zapatero & $\begin{array}{c}\text { 08 de abril } \\
\text { de } 2008\end{array}$ & $\begin{array}{c}\text { Disponível em: <http://bit. } \\
\text { ly/2Cyukxf } \\
\text { Acesso em: } 16 \text { mar. 2016. }\end{array}$ & 9.360 \\
\hline \multicolumn{3}{|c|}{ Total de Palavras } & 17.060 \\
\hline
\end{tabular}

De acordo com Esteban (2011), os discursos de investidura são discursos proferidos antes das eleições pelos candidatos a presidente do governo da Espanha, situação em que os candidatos buscam conquistar o apoio do Parlamento Espanhol ${ }^{12}$. Dessa forma, esperam obter o apoio dos grupos do parlamento para que alcancem os votos necessários para sua eleição, o que corrobora em maior manifestação da modalidade

\footnotetext{
10 Tradução dos tempos verbais da língua espanhola ao português. Em espanhol, os tempos verbais correspondem, respectivamente, segundo a Gramática da Real Academia Espanhola (2010), a: presente, pretérito perfectosimple, pretérito perfectocompuesto, pretérito pluscuamperfecto, pretérito imperfecto, condicional simple, condicional compuesto, futuro simple e futuro compuesto.

${ }^{11}$ Político espanhol que foi líder do Partido Socialista Obreiro Espanhol (PSOE) e presidente do governo da Espanha entre os anos de 2004 e 2011. Disponível em: <https://www. biografiasyvidas.com/biografia/r/rodriguez_zapatero.htm>. Acesso em: 09 jan. 2018.

${ }^{12}$ Composto pelos Senadores (Câmara Alta) e pelos Deputados (Câmara Baixa), que, para esta pesquisa, constituem o alvo da atitude volitiva.
} 
volitiva, haja vista que o candidato a primeiro-ministro discorreria a respeito do que lhe parece desejável em termos de ações políticas previstas para o seu mandato.

Retomando as categorias de análise citadas na seção 1, apresentamos o resumo delas no Quadro 2:

Quadro 2 - Categorias de análise para os aspectos semânticos e morfossintáticos da modalidade volitiva

\begin{tabular}{|c|c|}
\hline \multicolumn{2}{|c|}{ Aspectos Semânticos } \\
\hline \multirow{3}{*}{ Valores semânticos } & Volição \\
\hline & Volição-exortativa \\
\hline & Volição irrealizável \\
\hline \multirow{4}{*}{ Fonte volitiva } & Enunciador \\
\hline & Indivíduo \\
\hline & Instituição \\
\hline & Domínio Comum \\
\hline \multirow{4}{*}{ Alvo volitivo } & Enunciador \\
\hline & Indivíduo \\
\hline & Instituição \\
\hline & Coenunciador \\
\hline \multicolumn{2}{|c|}{ Aspectos Morfossintáticos } \\
\hline \multirow{9}{*}{ Tempo } & Presente \\
\hline & Pretérito Perfeito Simples \\
\hline & Pretérito Perfeito Composto \\
\hline & Pretérito Imperfeito \\
\hline & Pretérito mais-que-perfeito composto \\
\hline & Futuro Simples \\
\hline & Futuro Composto \\
\hline & Condicional Simples \\
\hline & Condicional Composto \\
\hline \multirow{3}{*}{ Modo } & Indicativo \\
\hline & Subjuntivo \\
\hline & Imperativo \\
\hline
\end{tabular}

Com base nessas categorias de análise, passemos agora à seção seguinte, que se refere às ocorrências de modalidade volitiva no corpus por nós selecionado em relação à fonte volitiva, ao alvo volitivo (aspectos semânticos) e à marcação do tempo e do modo verbais (aspectos morfossintáticos) utilizados pelo falante para a instauração das modalizações volitivas. 
v. 8 (esp.)

153-168 set. 2018

\section{Resultados: análise e discussão dos dados}

Nesta seção, apresentaremos os resultados, a análise e discussão dos dados com base na teoria da GDF e em trabalhos relativos à categoria modalidade volitiva. Começaremos apresentando os aspectos semânticos (fonte e alvo volitivos e o valor semântico instaurado) e depois seguiremos à apresentação dos aspectos morfossintáticos (tempo e modo verbais).

\section{Análise e discussão relativa aos aspectos semânticos}

Fonte volitiva

Em relação ao tipo de fonte volitiva, obtivemos 69 ocorrências de fonte volitiva, sendo 44 ocorrências do tipo "Enunciador", 13 do tipo "Instituição", 11 do tipo "Domínio Comum" e 1 do tipo "Indivíduo". Vejamos a Tabela 1:

Tabela 1 - Tipos de fonte volitiva encontrados no corpus

\begin{tabular}{ccc}
\hline Fonte Volitiva & Ocorrências & Porcentagem \\
\hline Enunciador & 44 & $63,76 \%$ \\
\hline Instituição & 13 & $18,85 \%$ \\
Domínio Comum & 11 & $15,95 \%$ \\
Indivíduo & 1 & $1,44 \%$ \\
Total & 69 & $100 \%$ \\
\hline
\end{tabular}

Como podemos constatar na Tabela 1, vimos que a fonte volitiva do tipo "Enunciador" foi a mais recorrente no corpus, haja vista que, para o discurso de investidura, o candidato a primeiro-ministro tende a manifestar seus desejos e vontades de realizar projetos políticos que atendam as expectativas daqueles que pensam em votar nele como primeiro-ministro do governo espanhol. Vejamos o dado (1):

(1) [...] Una coordinación que, mediante el diálogo y el acuerdo institucional con el Gobierno Vasco y con la Generalitat de Cataluña, quiero extender a las Fuerzas de Seguridad con que cuentan esas Comunidades [...] (ZAPATERO, 2004).

[Uma coordenação que, mediada pelo diálogo e pelo acordo institucional com o Governo Basco e com a Generalitat da Catalunha, quero estender às Forças de Segurança com que contam essas Comunidades [...]]. 
Em (1), notamos que o candidato a primeiro-ministro expressa seus desejos e vontades, fato constatado pelo emprego da primeira pessoa do singular, quiero (quero), em realizar reformas no corpo de segurança nacional, para garantir a segurança do Estado Espanhol, em especial, das Comunidades Autônomas da Catalunha e do País Basco (dois sujeitos distintos da ação desejada). Em relação à fonte do tipo "Enunciador", constatamos, também, certo grau de comprometimento no que diz respeito à ação desejada, haja vista que, caso venha a ser eleito, ao primeiro-ministro do governo ser-lhe-ia possível fazer reformas no corpo de segurança nacional. Devido a essa possibilidade, o candidato produz no(s) seu(s) ouvinte(s) a confiança necessária para que o estadode-coisas desejável do ponto de vista político se concretize, ainda que sejam desejos e anseios do candidato, podendo vir a ser realizados ou não.

Em (1), a utilização do modalizador volitivo pela fonte volitiva na primeira pessoa do singular, quiero (quero), legitima a concretização da ação desejada, já que ele, como primeiro-ministro, não apenas deseja, mas lhe é possível realizar, imprimindo em seu discurso maior acertabilidade do que é desejado em seu(s) destinatário(s), representado na eleição para primeiro-ministro do governo espanhol pela Cámara de los Diputados (Câmara dos Deputados). Segundo Oliveira, Nogueira e Prata (2017), o valor semântico instaurado é o de volição, que se trata do desejo propriamente dito. Nesses casos, ainda que o modalizador volitivo querer apresente-se em forma perifrástica, ele se comporta como um verbo léxico, pois carrega consigo a carga semântica da "intenção em realizar algo", conforme explica Oliveira (2017).

Sabendo que a ação desejada pela fonte volitiva (origem ou fonte da atitude volitiva) recai sobre um alvo volitivo (sujeito sobre quem recai a atitude volitiva), vejamos, na seção seguinte, os casos de alvo volitivo encontrados em nosso corpus.

Alvo volitivo

Em relação ao alvo volitivo, obtivemos 69 ocorrências de alvo da atitude volitiva, sendo: 53 do tipo "Instituição", 14 de "Indivíduo" e 2 de "Enunciador". Vejamos a Tabela 2: 
v. 8 (esp.)

153-168

set.

2018

Tabela 2 - Alvo volitivo em porcentagem (\%)

\begin{tabular}{ccc}
\hline Alvo Volitivo & Ocorrências & Porcentagem \\
\hline Instituição & 53 & $76,81 \%$ \\
\hline Indivíduo & 14 & $20,29 \%$ \\
Enunciador & 2 & $2,9 \%$ \\
Total & 69 & $100 \%$ \\
\hline
\end{tabular}

Como podemos constatar na Tabela 2, vimos que o alvo volitivo do tipo "Instituição" foi o mais recorrente na análise do corpus, o que se justifica pelo fato de a fonte volitiva instaurar seus desejos (volição) sobre instituições da esfera pública espanhola, como Sindicatos, Governos das Comunidades Autônomas, Órgãos responsáveis pela Educação, pela Saúde, pela Segurança Pública, etc., o que é justificável, haja vista que o plano de governo do seu partido, Partido Socialista Obreiro Espanhol (PSOE), está pautado na criação de políticas públicas que conciliem a sociedade com as instâncias do funcionalismo público, como em (2):

(2) [...] Radio Televisión Española y la Agencia EFE, a los que quiero liberar del control del Gobierno al que tradicionalmente han estado sometidos [...] (ZAPATERO, 2004).

[Rádio Televisão Espanhola e Agência EFE, a quem quero liberar do controle do governo a que tradicionalmente têm estado submissos [...]].

Em (2), a fonte volitiva expressa a desejabilidade de liberar do controle do governo o seu alvo volitivo (As Empresas de Rádio e Televisão). Vemos que a desejabilidade expressa pela fonte volitiva (candidato a primeiro-ministro) conquista a credibilidade por parte do alvo volitivo (Rádio e Televisão Espanholas), haja vista que parte de um agente que apresentará a capacidade e a autoridade necessária em concretizar a ação desejada caso venha a ser eleito como primeiro-ministro. Salientamos que as próprias características do discurso de investidura corroboram para que apresente maior incidência de alvo volitivo do tipo instituição, pois, ao discursar, o candidato terá que discorrer a respeito do que ele deseja realizar caso venha a ser eleito, devendo, pois, atender as necessidades sociais de todos, particularmente, das instituições públicas ou privadas que também colaboram na promoção de serviços que atendam as demandas sociais da população. 
Para que a fonte volitiva instaure a volição sobre o alvo volitivo, é necessário que a modalização volitiva seja, necessariamente, instaurada por meio de alguma expressão linguística. Por isso, vejamos agora o tempo e o modo verbais ${ }^{13}$ empregados pelo falante para a expressão de seus desejos (volição). Para o tempo e modo verbal, obtivemos 47 ocorrências (foram excluídos os casos em que a modalidade volitiva foi instaurada por meio de substantivos ou adjetivos em posição predicativa) que serão vistas nas subseções seguintes ${ }^{14}$.

\section{Análise e discussão relativa aos aspectos morfossintáticos}

Tempo verbal

Em relação ao tempo verbal empregado pelo falante para a instauração da modalidade volitiva, obtivemos 41 ocorrências de modalizadores volitivos no presente (presente), 3 ocorrências no pretérito perfeito composto (pretérito perfecto compuesto) e 3 ocorrências no pretérito imperfeito (pretérito imperfecto). Vejamos a Tabela 3:

Tabela 3 - Tempo verbal em porcentagem (\%)

\begin{tabular}{ccc}
\hline Tempo Verbal & Ocorrências & Porcentagem \\
\hline Presente & 41 & $87,24 \%$ \\
Pretérito Perfeito Composto & 3 & $6,38 \%$ \\
Pretérito Imperfeito & 3 & $6,38 \%$ \\
Total & 47 & $100 \%$ \\
\hline
\end{tabular}

Como podemos constatar na Tabela 3, vimos que o presente foi o tempo verbal mais empregado pelo falante (candidato a primeiroministro) para instaurar a modalidade volitiva. Vejamos (3):

(3) [...] Desde luego, a los Sindicatos, que siguen siendo hoy el mejor instrumento de participación de los trabajadores en las decisiones colectivas. Y, conellosy junto a ellos, las Organizaciones Empresariales.

\footnotetext{
${ }^{13}$ Consideramos essas duas categorias de análise por serem as mais recorrentes para a instauração da modalidade volitiva, já que o falante, majoritariamente, emprega verbos de significação plena ou auxiliares modais (verbos com marcação de tempo e modo).

${ }^{14}$ Para a marcação do tempo e modo verbal, o falante pode fazer uso de diferentes tipos de forma de expressão, tais como auxiliares modais (querer, desear, pretender, etc.), verbos de significação plena (desear, querer, anhelar, etc.) e construções volitivas com verbo suporte (que+subjuntivo, ojalá+subjuntivo, hacer votos, tener ganas, etc.).
} 
v. 8 (esp.)

153-168 set. 2018

Con ambos, quiero desarrollar un diálogo social fecundo que asegure el crecimiento económico y la participación efectiva de todos los ciudadanos en el bienestar social (ZAPATERO, 2004).

[É claro, para os sindicatos, que ainda são hoje o melhor instrumento para a participação dos trabalhadores nas decisões coletivas. E, com eles e próximo a eles, as Organizações Empresariais. Com ambos, quero desenvolver um diálogo social fecundo que assegure o crescimento econômico e a participação efetiva de todos os cidadãos para o bem-estar social.].

Em (3), o candidato a primeiro-ministro faz uso do presente do indicativo para a instauração da modalidade volitiva em relação a um desejo seu de que, no seu mandado, haja maior diálogo entre o governo e os sindicatos e as organizações empresariais. Constatamos que o falante, ainda que se refira a projeções futuras, já que discursa visando ganhar as eleições para primeiro-ministro, emprega o presente do indicativo. De acordo com Martínez, Manzano e Barriendos (2004), quando o falante emprega uma forma no presente para descrever um evento futuro, ele o faz devido ao caráter de "atualização da informação" que o tempo presente atrai para si, já que o presente do indicativo é de caráter factual. Em outras palavras, a descrição de um evento ou projeções futuras por meio de uma forma factual faz com que o evento ou essas projeções se interpretem como um fato concreto e não como uma mera hipótese. Em (3), o falante faz uso, respectivamente, da locução prepositiva desde luego (sem dúvida) para ressaltar que o evento volitivo "promover diálogo entre o governo, os sindicatos e as organizações empresariais" não se trata apenas de uma mera hipótese ou algo de que se possa duvidar, mas de uma "disposição sua em potencializar o evento volitivo manifestado". Em (2) e (3), de acordo com Oliveira, Nogueira e Prata (2017), o valor semântico é o de volição (que se refere ao desejo propriamente dito).

Na análise das ocorrências do nosso corpus, pudemos constatar uma predominância do modo indicativo (presente e o pretérito perfeito composto) e algumas poucas ocorrências no modo subjuntivo (pretérito imperfeito), como veremos na subseção seguinte. 
Modo verbal

Em relação ao modo verbal empregado pelo falante para a instauração da modalidade volitiva, obtivemos 44 ocorrências de modalizadores volitivos no modo indicativo e 3 ocorrências no modo subjuntivo. Vejamos a Tabela 4:

Tabela 4 - Modo verbal em porcentagem (\%)

\begin{tabular}{ccc}
\hline Modo Verbal & Ocorrências & Porcentagem \\
\hline Indicativo & 44 & $93,62 \%$ \\
\hline Subjuntivo & 3 & $6,38 \%$ \\
Total & 47 & $100 \%$ \\
\hline
\end{tabular}

Como podemos constatar na Tabela 4, vimos que o indicativo foi o modo verbal mais empregado pelo falante (candidato a primeiroministro) para instaurar a modalidade volitiva. Vejamos (4):

(4) [...] El país que quiero no puede tolerar que cada semana muera una mujer por la violencia machista. La política desarrollada en la legislatura pasada ha servido para mejorar la situación de las mujeres víctimas de violencia, y para salvar muchas vidas. Pero no ha sido suficiente [...] (ZAPATERO, 2008).

[O país que quero não pode tolerar que cada semana uma mulher morra por causa do machismo. A política desenvolvida na legislatura passada serviu para melhorar a situação das mulheres vítimas de violência, e para salvar muitas vidas. Mas não foi o suficiente [...]].

Em (4), vemos que o candidato a primeiro-ministro expressa seu desejo (volição) de que haja um novo país em que não seja mais tolerado qualquer tipo de violência contra a mulher (violência de gênero). Para a instauração da desejabilidade, o falante emprega o verbo de significação plena, no caso, o verbo querer. O uso do modo indicativo na maioria das ocorrências, segundo a Gramática da Real Academia Espanhola - GRAE (2010), deve-se ao fato de que o modo indicativo refere-se a ações que o falante entende como reais e factuais. Em (4), a desejabilidade de que se construa uma Espanha em que se erradique a violência de gênero se refere a um estado-de-coisas real e possível de concretizar, desde que sejam promovidas políticas públicas para isso. Por isso, acreditamos que o número percentual de ocorrências de instauração da modalidade 
v. 8 (esp.)

153-168 set. 2018

volitiva, no modo indicativo, deve-se ao fato de o indicativo expressar não apenas ações reais, mas certas e/ou perfeitas. Dessa forma, é plausível que, para fazer menção a ações políticas concretas, reais e assertivas para o(s) seu(s) destinatário(s), o falante faça uso dos modalizadores volitivos no modo indicativo. Em outras palavras, a volição expressa está relacionada ao presente (o ato de querer), enquanto que o estadode-coisas apresentado ganha projeção futura.

Vejamos (5):

(5) [...] quiero instituir una Conferencia de Presidentes, que nos reúna a quienes ejercemos los Gobiernos de todo el Estado y de cada una de las Comunidades. Una Conferencia cuya primera reunión quisiera celebrarla en el último trimestre del presente año [...] (ZAPATERO, 2004).

[[...] quero instituir uma Conferência de Presidentes, que reúna a todos aqueles que exercem algum cargo, os Governos de todo o Estado e de cada uma das Comunidades. Uma Conferência cuja primeira reunião quisesse celebrá-la no último trimestre do presente ano [...]].

Em (5), vemos que o candidato a primeiro-ministro faz uso tanto do modo indicativo quanto no modo subjuntivo para referir-se a um mesmo estado-de-coisas (realização de uma conferência com todos os governos das Comunidades Autônomas que formam o Reino da Espanha) ${ }^{15}$. O emprego do modo indicativo, quiero instituir (quero instituir), justifica-se pela real possibilidade de que seja instituída uma conferência nacional com todos os governos caso o candidato venha a ser eleito, referindo-se a um estado-de-coisas possível, real e concreto; enquanto o emprego do modo subjuntivo, quisiera celebrarla (quisesse celebrá-la), explica-se pela eventual possibilidade de que essa conferência venha a acontecer no último trimestre do ano de 2004, o que dependeria da agenda dos governos das Comunidades Autônomas e dependendo também da vitória nas eleições para primeiroministro do governo espanhol. Vale ressaltar que o emprego da primeira pessoa do singular no pretérito imperfeito do subjuntivo poderia referir-se também como algo cortês e polido da parte do candidato.

Em (4) e (5), também constatamos que a modalização volitiva instaurada apresenta o valor semântico de volição (o desejo propriamente dito). Segundo a Gramática da Real Academia Espanhola (2010), a escolha

\footnotetext{
${ }^{15}$ Nome oficial dado ao Estado Espanhol pela Constituição Espanhola de 1978.
} 
pelo emprego do modo indicativo por parte do falante dependerá da atitude do próprio falante frente à ação verbal que ele enuncia; dessa forma, podemos dizer que o emprego do indicativo tratar-se-á de ações nas quais o falante versa sobre estado-de-coisas reais e objetivos (a realização de uma Conferência com todos os governos das demais Comunidades Autônomas), enquanto que o falante fará uso do modo subjuntivo quando se referir a ações hipotéticas e subjetivas (primeira Conferência no último trimestre de 2004).

\section{Considerações finais}

Procuramos apresentar, neste trabalho, os aspectos semânticos e os aspectos morfossintáticos da modalidade volitiva instaurados em um texto de caráter argumentativo e político, o discurso de investidura. A escolha desse tipo de texto argumentativo se deu por acreditarmos que haveria a possibilidade de manifestação de modalizações volitivas, haja vista que seria propício que o falante (o candidato a primeiro-ministro do governo espanhol) manifestasse seus desejos e intenções acerca das suas pretensões políticas em seu futuro mandato.

No que diz respeito à fonte volitiva, constatamos que houve uma predominância do tipo de fonte "Enunciador" (63,76\%), já que esse tipo de fonte legitima a concretização da ação desejada, pois lhe é possível realizar o que é desejado, o que garante a acertabilidade de seu discurso a respeito do que ele deseja ao(s) seu(s) destinatário(s).

Em relação ao alvo volitivo, verificamos maior ocorrência de alvo do tipo "Instituição" (76,81\%), que se justifica pelo fato de a fonte volitiva tratarse de um agente que, caso venha a ser eleito, terá a autoridade necessária para concretizar a ação desejada, atendendo, assim, as necessidades sociais de todos, em especial, das instituições públicas ou privadas (alvo volitivo) que também são relevantes em atender as demandas sociais.

Em relação aos aspectos morfossintáticos, averiguamos que houve uma predominância do presente do modo indicativo (87,24\%); o que se explica, tendo em vista que o presente do indicativo (de caráter factual) descreve ações que atualizam a informação ou a desejabilidade de um dado evento ou ação, fazendo com que o falante modalize a respeito de um desejo (volição) como algo concreto e possível de realizar-se. Em relação ao modo verbal, verificamos que o modo indicativo foi o mais utilizado pelo falante (93,62\%), o que já era esperado, considerando que o modo indicativo referese a estado-de-coisas desejáveis ou a ações políticas como algo real, certo e possível de concretizar-se e pela necessidade de que seu discurso verse sobre algo concreto, real e assertivo para o(s) seu(s) destinatário(s). 
v. 8 (esp.)

153-168 set. 2018

Acreditamos que este trabalho possa, de alguma forma, contribuir para os estudos relativos à modalidade volitiva, tendo em vista, como aponta Oliveira (2017), que esta categoria de modalidade é apresentada, em algumas tipologias, ora como um tipo distinto de modalidade, ora como um subtipo da modalidade deôntica, ora como uma categoria acima da modalidade, a Volitividade.

\section{Referências}

DALL'AGLIO HATTNHER, M. M.; HENGEVELD, K. The Grammaticalization of Modal Verbs in Brazilian Portuguese: A Synchronic Approach. Journal of Portuguese Linguistics, n. 1, v. 15, 2016. Disponível em: <http://zip.net/ bltBtQ>. Acesso em: 08 jan. 2017.

ESTEBAN, R. A. El discurso de investidura como instrumento de comunicación política en España (1979-2008). 2011. Disponível em: <http://zip.net/brtsCc>. Acesso em: 02 jul. 2016.

GARCÍA, E. J. Un estudio comparado de partículas modales en ruso y en español. 2009. Tese (Doutorado em Filologia) - Programa de Pós-Graduação em Filologia Grega e Eslava, Universidade de Granada, Espanha. Disponível em: <http://zip.net/bxts99>. Acesso em: 18 mar. 2016.

GRAMÁTICA DE LA REAL ACADEMIA ESPAÑOLA. 2010. Espasa Libros S. L.: Madrid, 2010.

HENGEVELD, K.; MACKENZIE, J. L. Functional Discourse Grammar: a typologically-based theory of language structure. Oxford: Oxford Linguistics, 2008.

MARTÍNEZ, F. P; MANZANO, P.G; BARRIENDOS, M. S. Presente, ir a + infinitivo y futuro: ¿expresan lo mismo cuando se habla del futuro? 2004. Centro Virtual Cervantes - ASELE, Actas XV, 2004. Disponível em: <http://zip.net/bhtzsg>. Acesso em: 27 dez. 2016.

OLIVEIRA, A. S.; NOGUEIRA, M. T.; PRATA, N. P. P. A modalidade volitiva em língua espanhola: uma análise funcionalista em discursos de investidura. In: PRATA, N. P. P.; PEREIRA, G. C.; PONTES, V. O.; ADERALDO, M. F. Espanhol em Pauta: perspectivas teórico-analíticas. Curitiba: Editora Appris, 2017.

OLIVEIRA, A. S. Modalidade volitiva em língua espanhola nos discursos do Papa Francisco em viagem apostólica. 2017. 310f. Dissertação (Mestrado em Linguística) - Programa de Pós-Graduação em Linguística. Universidade Federal do Ceará (UFC), Fortaleza. 2017. Disponivel em: <http://bit. ly/2odUwqY>. Acesso em: 14 dez. 2017.

PESSOA, N. P. Modalidade deôntica e discurso midiático: uma análise baseada na Gramática Discursivo-Funcional. 2011. Tese (Doutorado em Linguística) Programa de Pós-Graduação em Linguística, UFC, Fortaleza. Disponível em: <http://bit.ly/2CtFQuz>. Acesso em: 14 dez. 2017. 